\title{
Traumatic Pneumothorax Secondary to Acupuncture Needling
}

\author{
Ching-Hui Sia ${ }^{1}$, Aloysius Sheng-Ting Leow ${ }^{2}$, Benjamin Sieu-Hon Leong ${ }^{3}$ \\ 1. Department of Cardiology, National University Health System, Singapore, Singapore, SGP 2. Yong Loo Lin School of \\ Medicine, Singapore, SGP 3. Department of Emergency Medicine, National University Health System, Singapore, SGP
}

Corresponding author: Aloysius Sheng-Ting Leow, leowaloysius@hotmail.com

\begin{abstract}
Acupuncture is a common form of therapy involving insertion of fine needles to alleviate nausea and various forms of pain. We describe a case of pneumothorax secondary to acupuncture.
\end{abstract}

A 50-year-old woman presented to the emergency department with right-sided pleuritic chest pain. This was following a history of acupuncture and cupping treatment an hour earlier at a traditional practitioner for long-standing neck pain. On physical examination, the respiratory rate was 22 breaths per minute and her oxygen saturation was $100 \%$ on room air. Breath sounds were decreased on the right hemithorax with hyper resonance to percussion. Inspection of her back revealed multiple needling and cupping marks. A chest radiograph revealed a right-sided pneumothorax with an apex-cupola distance of $3.6 \mathrm{~cm}$. She was put on high flow oxygen and a chest tube was inserted into the right chest wall. The patient was admitted. She had radiographic resolution of the pneumothorax four days later and was discharged uneventfully. Follow-up one week later in the clinic showed no radiographic recurrence of the pneumothorax.

Received 03/19/2018

Review began 03/21/2018

Review ended 08/21/2018

Published 08/23/2018

๑) Copyright 2018

Sia et al. This is an open access article distributed under the terms of the Creative Commons Attribution License CC-BY 3.0., which permits unrestricted use, distribution, and reproduction in any medium, provided the original author and source are credited.
Categories: Emergency Medicine, Internal Medicine, Pulmonology

Keywords: acupuncture, chest pain, needling, pneumothorax

\section{Introduction}

Acupuncture is a form of therapy involving insertion of fine needles into specific sites on the body within the subcutaneous layer [1]. While commonly used to alleviate nausea [2] and various forms of pain [3,4], serious adverse events such as pneumothorax, septicemia and spinal cord injury should not be overlooked [5]. The following case report describes a case of pneumothorax secondary to acupuncture.

\section{Case Presentation}

A 50-year-old Chinese lady presented to our emergency department with right-sided chest pain. She had a history of De Quervain's tenosynovitis of the left hand post-release seven years earlier and was a nonsmoker.

She complained of right-sided chest pain on deep inspiration. She had just sought treatment at a traditional medicine practitioner for a session of acupuncture and cupping ('ba guan') to the back to treat her symptoms of long-standing neck pain and intermittent numbness and tingling of both hands. This pain occurred while she was sitting down after receiving treatment. She denies any trauma to her chest. She did have some difficulty taking in breaths due to the chest pain. There was no fever, cough, runny nose or sore throat.

Physical examination revealed that she was afebrile, had a blood pressure of 99/63 mmHg, heart rate of 96 beats per minute, respiratory rate of 22 per minute and an oxygen saturation of $100 \%$ on room air. She was alert, comfortable and conversant in full sentences. Her heart sounds were dual, with no clicks, rubs or murmurs. Breath sounds were slightly decreased on the right but otherwise no crepitations were heard. Inspection of her back is as shown in Figure 1, with multiple cupping and needling marks. Her abdomen was soft and non-tender. She had supple calves and no pedal edema on examination. 


\section{Cureus}

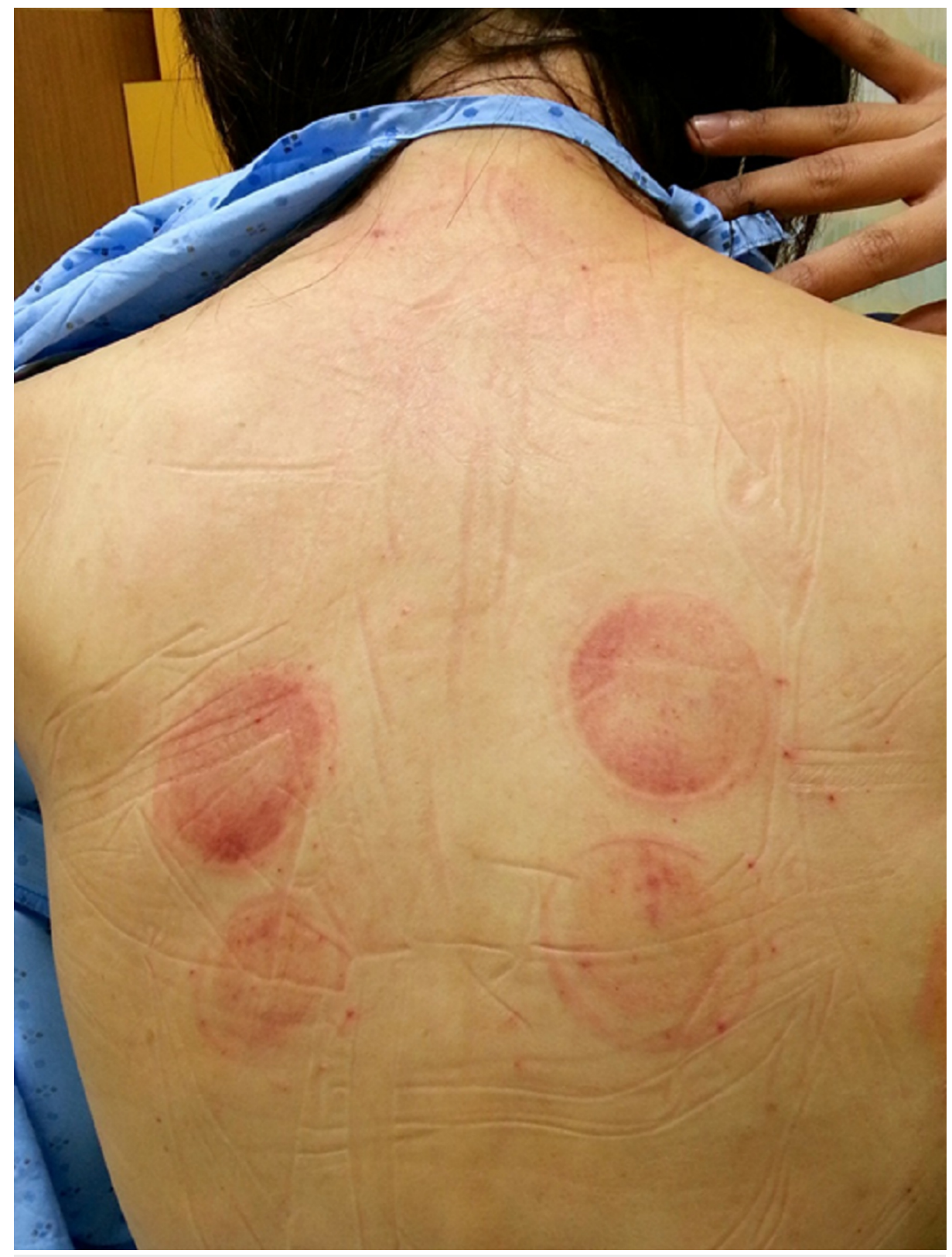

\section{FIGURE 1: Back of the patient on initial examination.}

Initial investigations revealed a normal complete blood count and metabolic panel. Electrocardiogram showed normal sinus rhythm with no acute ST segment or T wave changes. The chest radiograph on admission is as shown in Figure 2, with a right-sided pneumothorax with an apical-cupola distance of 3.6 $\mathrm{cm}$. 


\section{Cureus}

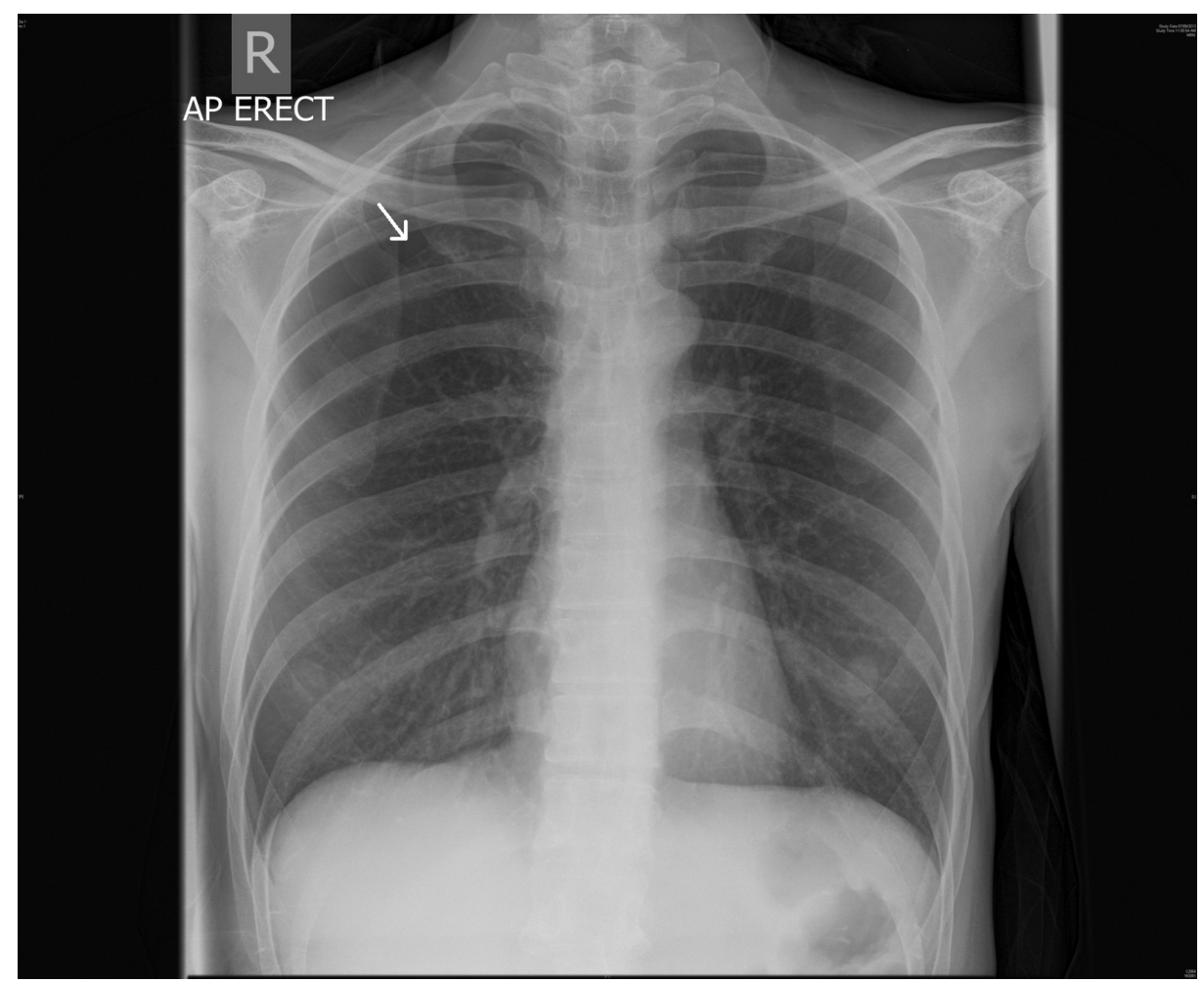

FIGURE 2: Right apical pneumothorax with apex-cupola distance of 3.6 cm.

Subsequently, the patient was put on a non-rebreather mask with a FiO2 of $100 \%$ and a 12 French chest tube was inserted via the Seldinger's technique into the right chest wall in the emergency department. The patient was admitted to the Respiratory service with radiographic resolution of the pneumothorax within four days and was discharged when the apex-cupola distance of the pneumothorax was $4 \mathrm{~mm}$. A repeat chest radiograph a week later in the follow-up clinic showed complete resolution of the pneumothorax (Figure 3). 


\section{Cureus}

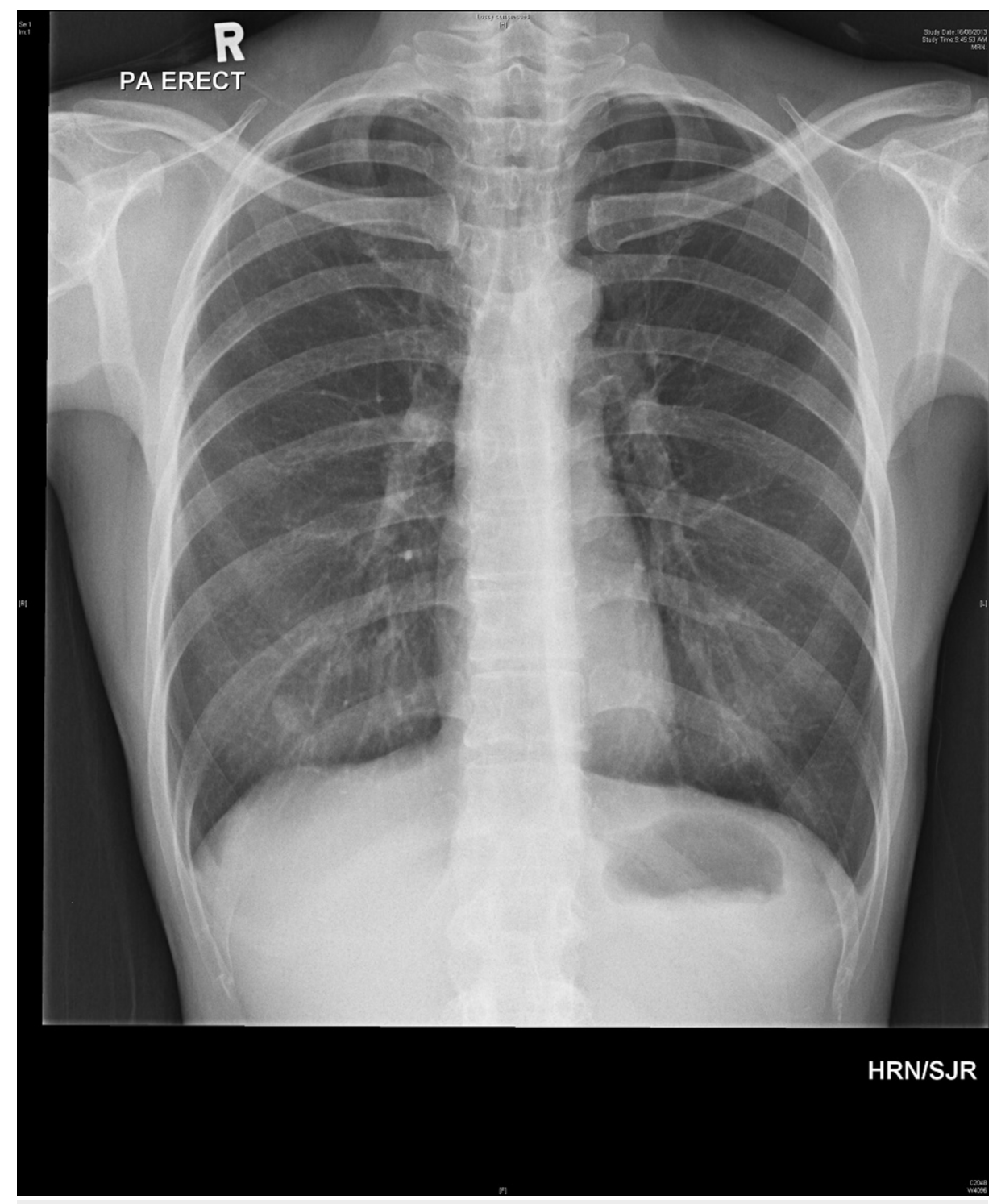

FIGURE 3: Resolution of pneumothorax on follow-up.

\section{Discussion}

We report a rare case of a traumatic pneumothorax secondary to acupuncture needling. The exact incidence of this condition is unknown, but a systematic review has estimated it to occur in twice in nearly a quarter of a million treatments [6]. Based on our knowledge, this is the first published image of a patient's back together with a corresponding chest radiograph.

Acupuncture is widely considered to be a safe alternative to Western medicine and there has been increasing interest by patients in seeking this form of treatment for their ailments. Common uses (not necessarily evidence-based) include management for pain, addiction management, menopausal symptom control, for cancer and post-operative conditions [2-5].

However, considerable serious adverse events exist which the medical practitioner should know about. Common events include fainting, nausea and vomiting, pain, diarrhea, local skin bruising or bleeding, psychiatric disturbances, headaches, sweating, dizziness, aggravation of symptoms or needle breakage. More serious complications reported include pneumothorax (with or without tension), spinal cord injury, cardiac tamponade, staphylococcal septicemia, hepatitis B/C/HIV infection, convulsions and even death [5]. Su et al. presented a case of bilateral tension pneumothorax in an unfortunate lady at their institution [7].

In cases of suspected pneumothorax associated with acupuncture, we suggest performing a thorough physical examination including inspection of the back to look for any needling marks. This is often overlooked in a busy clinical environment such as the emergency department or when the patient is clothed. A review by the World Health Organization on complications of acupuncture showed that acupuncture- 
associated pneumothoraces had puncture sites mainly in the shoulder and scapular regions (64\%) and in the chest (24\%) [8]. This corresponded with our case. As immediate radiography of the chest may not reveal the presence of the pneumothorax, a repeat chest radiograph after 24 hours is recommended if suspicion is high [9]. On the other hand, various studies have reported higher sensitivity of point-of-care ultrasound than chest radiograph in identifying pneumothorax, which underlies its increasing use these days and would be a valuable modality when evaluating patients with suspected pneumothorax [10,11].

\section{Conclusions}

Recent history of treatment by a traditional medicine practitioner should raise one's suspicion for acupuncture-associated pneumothorax and requires careful history and physical examination to correlate onset of symptoms with the procedure.

\section{Additional Information}

\section{Disclosures}

Human subjects: Consent was obtained by all participants in this study. Conflicts of interest: In compliance with the ICMJE uniform disclosure form, all authors declare the following: Payment/services info: All authors have declared that no financial support was received from any organization for the submitted work. Financial relationships: All authors have declared that they have no financial relationships at present or within the previous three years with any organizations that might have an interest in the submitted work. Other relationships: All authors have declared that there are no other relationships or activities that could appear to have influenced the submitted work.

\section{References}

1. White A, Editorial Board of Acupuncture in Medicine: Western medical acupuncture: a definition. Acupunct Med. 2009, 27:33-35. 10.1136/aim.2008.000372

2. Lee A, Fan L: Stimulation of the wrist acupuncture point $\mathrm{P} 6$ for preventing postoperative nausea and vomiting. Cochrane Database Syst Rev. 2009, CD003281. 10.1002/14651858.CD003281.pub3

3. Sun Y, Gan TJ, Dubose J, Habib A: Acupuncture and related techniques for postoperative pain: a systematic review of randomized controlled trials. Br J Anaesth. 2008, 101:151-160. 10.1093/bja/aen146

4. Brinkhaus B, Witt CM, Jena S, et al.: Acupuncture in patients with chronic low back pain: a randomized controlled trial. Arch Intern Med. 2006, 166:450-457. 10.1001/archinte.166.4.450

5. Chung A, Bui L, Mills E: Adverse effects of acupuncture. Which are clinically significant? . Can Fam Physician. 2003, 49:985-989.

6. Ernst E, White AR: Prospective studies of the safety of acupuncture: a systematic review . Am J Med. 2001, 110:481-485. 10.1016/S0002-9343(01)00651-9

7. Su J, Lim C, Chua Y: Bilateral pneumothoraces as a complication of acupuncture . Singapore Med J. 2007, 48:32-33.

8. Zhang J, Shang H, Gao X, Ernst E: Acupuncture-related adverse events: a systematic review of the Chinese literature. Bull World Health Organ. 2010, 88:915-921. 10.2471/BLT.10.076737

9. Ritter HG, Tarala R: Pneumothorax after acupuncture. BMJ. 1978, 2:602-603.

10. Blaivas M, Lyon M, Duggal S: A prospective comparison of supine chest radiography and bedside ultrasound for the diagnosis of traumatic pneumothorax. Acad Emerg Med. 2005, 12:844-849. 10.1197/j.aem.2005.05.005

11. Gentry Wilkerson R, Stone MB: Sensitivity of bedside ultrasound and supine anteroposterior chest radiographs for the identification of pneumothorax after blunt trauma. Acad Emerg Med. 2010, 17:11-17. 10.1111/j.1553-2712.2009.00628.x 